\title{
The clinical significance of preoperative serum fibrinogen levels and platelet counts in patients with gallbladder carcinoma
}

Peng Cao ${ }^{1,2}$, Lei Jiang ${ }^{2}$, Liang-Yi Zhou ${ }^{2}$ and Yan-Ling Chen ${ }^{2^{*}}$

\begin{abstract}
Background: Gallbladder carcinoma (GBC) was the most common malignancy of biliary tract. Patients with malignancies frequently present with activated coagulation pathways, which might potentially related to tumor progression and prognosis. The purpose of the study was to investigate the clinical significance of preoperative serum fibrinogen levels and platelet counts in GBC patients.
\end{abstract}

Methods: The preoperative fasting serum fibrinogen levels and platelet counts of 58 patients with GBC were measured by AUV2700 automatic biochemical analyzer, as well as 60 patients with cholesterol polyps and 60 healthy volunteers. Kaplan-Meier survival analysis was applied to show the correction between fibrinogen levels and outcome after surgery.

Results: The fibrinogen levels of patients with GBC were significantly higher than healthy gallbladder and cholesterol polyp of gallbladder ( $p<0.001$ and $p<0.001$, respectively). In GBC, fibrinogen levels were associated with tumor depth $(p=0.001)$, lymph node metastasis $(p=0.002)$, distant metastasis $(p<0.001)$ and Tumor Node Metastasis (TNM) stage $(p<0.001)$. The levels in TNM stage IV disease were significantly higher than stage III or stage I + II disease $(p=0.048$ and $p<0.001$, respectively), and in TNM stage III disease were significantly higher than stage I+ II disease $(p=0.002)$. Furthermore, the overall survival was better in low fibrinogen level group than in high fibrinogen level group ( $p<0.001)$. However, thrombocytosis was not significantly associated with overall survivals $(p>0.05)$ in multivariate analysis.

Conclusions: The preoperative serum fibrinogen levels and platelet counts might be reliable biomarkers for the occurance of disease, tumor depth, lymph node metastasis, distant metastasis and advanced TNM stage in patients with GBC. The serum fibrinogen levels might be a prognostic factor to predict outcome for GBC patients suffering from surgery treatment. Anticoagulation therapy might be considered to control cancer progression in future studies.

Keywords: Gallbladder carcinoma, Hyperfibrinogenemia, Thrombocytosis, Lymph nodes metastases, Distant metastasis, TNM stage, Prognosis

*Correspondence: drchenyl@126.com

${ }^{2}$ Department of Hepatobiliary Surgery and Fujian Institute

of Hepatobiliary Surgery, Fujian Medical University Union Hospital, Fujian

Medical University Cancer Center, Fuzhou, China

Full list of author information is available at the end of the article

\begin{abstract}
Background
Primary gallbladder carcinoma $(\mathrm{GBC})$ was one of the most common and malignant carcinoma of the biliary tract and was the sixth most common cancer of gastrointestinal tract [1]. Radical resection was the most effective treatment [2]. However, GBC was asymptomatic and was difficult to diagnose without suspicion in the
\end{abstract}

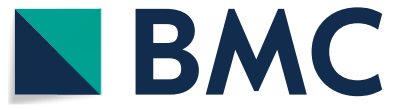

(c) The Author(s) 2021. Open Access This article is licensed under a Creative Commons Attribution 4.0 International License, which permits use, sharing, adaptation, distribution and reproduction in any medium or format, as long as you give appropriate credit to the original author(s) and the source, provide a link to the Creative Commons licence, and indicate if changes were made. The images or other third party material in this article are included in the article's Creative Commons licence, unless indicated otherwise in a credit line to the material. If material is not included in the article's Creative Commons licence and your intended use is not permitted by statutory regulation or exceeds the permitted use, you will need to obtain permission directly from the copyright holder. To view a copy of this licence, visit http://creativecommons.org/licenses/by/4.0/. The Creative Commons Public Domain Dedication waiver (http://creativeco mmons.org/publicdomain/zero/1.0/) applies to the data made available in this article, unless otherwise stated in a credit line to the data. 
early stage of occurrence, when the accurate diagnosis was made, radical cure often couldn't be performed due to direct invasion into adjacent structures such as the hepatic artery or the portal vein [3], as well as metastasis via the lymphatic, perineural, and hematogenous routes [4], which resulting in poor overall prognosis [5]. Tumor depth,lymph node metastasis, distant metastasis and TNM stage were closely related to prognosis of GBC. So it was important to find effective biomarkers to recognize unique biological characteristics of GBC patients, and to guide more individualized treatment.

It is suggested that the alteration of coagulation pathways was related with tumor progression and poor prognosis in various malignancies [6, 7]. Hemostatic parameters were found abnormal in more than half of patients with metastatic disease [8]. Fibrinogen was an dimeric glycoprotein synthesized by hepatocytes [9], lung [10] and intestinal epithelium [11], which played a key role in blood clotting, fibrinolysis, inflammatory response, wound healing and neoplasia [12]. Under pathological states, the coagulant molecules from tumor cells which promoted the increase of fibrinogen [13]. Elevated serum fibrinogen levels reflected a thrombophilic state and influenced cancer cell growth, progression and metastasis. Recently, the serum fibrinogen levels were found to correlate with clinicopathological factors and prognosis in colorectal cancer [14], hepatic cancer [15], osteosarcoma [6, 7], malignant soft tissue tumors [11], pancreatic cancers [16], gastric cancer [17], and ovarian cancer [18]. These previous study suggested that the alteration of serum pre-therapeutic fibrinogen levels was a useful predictor of therapeutic response and prognosis. However, no study has determined the significance of serum fibrinogen levels in GBC patients as a predictor of survival after surgical treatment.

Platelet is another crucial player of the coagulation system. Platelet could facilitate metastasis by promoting disseminated tumor cell survival in the circulatory system, and extravasation and angiogenesis in the microenvironment of target sites [19]. Several previous studies have suggested that an elevated platelet count related to poor prognosis in solid malignancies, including colorectal cancer [14], hepatic cancer [15], osteosarcoma [6, 7], malignant soft tissue tumors [11], pancreatic cancers [16], gastric cancer [17], and ovarian cancer [18], etc.

In the present study, we examined the clinical significance of preoperative serum fibrinogen levels and platelet counts in GBC treated by surgical treatment.

\section{Methods}

\section{Study population}

A total of 58 patients who underwent surgery for GBC in Affiliated Union Hospital of Fujian Medical University between October 2008 and October 2017 were included in the study. Patients were already excluded because of incomplete clinical data, palliative radiotherapy or chemotherapy, preoperative mortality and lost to follow-up. Based on the clinical records, the following data were collected for each patient: age, gender, T stage and other miscellaneous characteristics. All cases were staged clinically according to the American Joint Committee on Cancer (AJCC, 7th). The clinic pathological characteristics of GBC patients were presented in Table 1.

Moreover, we choosed 60 patients as another group: 60 patients with cholesterol polyps, treated by surgery in the Affiliated Union Hospital of Fujian Medical University. The control group included 60 healthy volunteers. All cases didn't have received any preoperative radiochemotherapy or transfusion, and all cases without coronary heart disease, cerebrovascular disease, arteriosclerosis, liver disease, COPD, thrombotic diseases, acute inflammation etc. All subjects provided their written informed consent, and the study was conducted with the approval of the institutional Ethics Committees of Fujian Medical University.

\section{Fibrinogen levels and platelet counts measurement}

Venous blood samples were collected according to standard hospital clinical routine within 24 h to 1 week before surgery or anticancer after overnight fasting and measured by AUV2700 automatic biochemical analyzer (Olympus, Japan). Plasma fibrinogen levels and platelet counts greater than $4.0 \mathrm{~g} / \mathrm{L}$ and $300 \times 10^{9} / \mathrm{L}$ were defined as hyperfibrinogenemia and thrombocytosis, respectively, according to the normal reference range in our hospital.

\section{Follow-up assessments}

All of the patients were followed by telephone interviews. The duration of follow-up was defined from the date of operation to the date of the last follow-up before the data were analyzed, or the date of death. The patients received follow-up until October 2020. The patients were followed up every 3 months during the first two postoperative years, every 6 months for the next year. Physical examination, chest radiography, peripheral blood tumor marker measurements (CA199 and AFP), and abdominal computed tomography or magnetic resonance imaging were performed during the follow-up period. The median follow-up duration was 13.6 months (range 1.5-36 months). The follow-up rate of this study was $87.9 \%$.

\section{Comorbidity}

Hypertension was delimited by using antihypertensive medications or in the presence of a diastolic BP of more than $90 \mathrm{~mm} \mathrm{Hg}$, a systolic BP level of more than $140 \mathrm{~mm}$ 
Table.1 Association between serum fibrinogen levels and platelet counts with clinicopathological characteristics

\begin{tabular}{|c|c|c|c|c|c|}
\hline Item & Number & Fibrinogen (g/L) & $\mathbf{P}$ & Platelet count $\left(\times 10^{9} / \mathrm{L}\right)$ & $\mathbf{P}$ \\
\hline \multicolumn{6}{|l|}{ Age (years) } \\
\hline$<65$ & $17(29.31)$ & $4.33 \pm 1.23$ & & $270.59 \pm 98.90$ & \\
\hline$\geq 65$ & $41(70.69)$ & $4.29 \pm 1.39$ & 0.893 & $248.39 \pm 80.39$ & 0.375 \\
\hline \multicolumn{6}{|l|}{ Gender } \\
\hline Female & $25(43.10)$ & $4.20 \pm 1.17$ & & $246.40 \pm 80.93$ & \\
\hline Male & $33(56.90)$ & $4.41 \pm 1.54$ & 0.557 & $261.33 \pm 90.24$ & 0.517 \\
\hline \multicolumn{6}{|c|}{ Tumor location } \\
\hline Neck & $33(56.90)$ & $4.50 \pm 1.19$ & & $261.73 \pm 81.45$ & \\
\hline Others & $25(43.10)$ & $4.01 \pm 1.48$ & 0.164 & $245.88 \pm 92.44$ & 0.492 \\
\hline \multicolumn{6}{|l|}{ Tumor size } \\
\hline$<4 \mathrm{~cm}$ & $40(68.97)$ & $3.29 \pm 1.35$ & & $265.53 \pm 78.19$ & \\
\hline$\geq 4 \mathrm{~cm}$ & $18(31.03)$ & $3.35 \pm 1.34$ & 0.886 & $250.03 \pm 91.17$ & 0.529 \\
\hline \multicolumn{6}{|l|}{ Histology } \\
\hline Adeno & $42(72.41)$ & $3.87 \pm 1.06$ & & $256.80 \pm 87.51$ & \\
\hline Other types & $16(27.59)$ & $4.32 \pm 1.35$ & 0.519 & $229.25 \pm 63.99$ & 0.541 \\
\hline \multicolumn{6}{|c|}{ Histological grading } \\
\hline Poorly & $31(53.45)$ & $4.59 \pm 1.34$ & & $262.48 \pm 81.01$ & \\
\hline Moderately & $18(31.03)$ & $4.00 \pm 1.18$ & & $244.00 \pm 107.75$ & \\
\hline High & $9(15.52)$ & $3.83 \pm 1.47$ & 0.174 & $250.56 \pm 53.14$ & 0.764 \\
\hline \multicolumn{6}{|l|}{ Tumor depth } \\
\hline $0-\|$ & $7(12.07)$ & $2.74 \pm 0.69$ & & $247.71 \pm 35.99$ & \\
\hline III-IV & $51(87.93)$ & $4.50 \pm 1.26$ & 0.001 & $255.88 \pm 90.86$ & 0.816 \\
\hline \multicolumn{6}{|l|}{ LN metastasis } \\
\hline NO & $24(41.38)$ & $1.87 \pm 0.58$ & & $249.47 \pm 78.78$ & \\
\hline N1 & $16(27.59)$ & $3.12 \pm 0.88$ & & $251.45 \pm 93.00$ & \\
\hline $\mathrm{N} 2$ & $18(31.03)$ & $4.41 \pm 0.90$ & 0.002 & $262.57 \pm 88.13$ & 0.879 \\
\hline \multicolumn{6}{|c|}{ Distant metastasis } \\
\hline Mo & $40(68.97)$ & $2.69 \pm 1.13$ & & $239.85 \pm 84.39$ & \\
\hline M1 & $18(31.03)$ & $4.62 \pm 0.69$ & 0.0002 & $288.33 \pm 81.90$ & 0.046 \\
\hline \multicolumn{6}{|l|}{ TNM stage } \\
\hline $\mid+\|$ & $7(12.07)$ & $2.69 \pm 0.62$ & & $247.86 \pm 36.04$ & \\
\hline III & $25(43.11)$ & $4.16 \pm 1.12$ & & $231.96 \pm 92.87$ & \\
\hline IV & $26(44.82)$ & $4.85 \pm 1.30$ & 0.0002 & $278.85 \pm 84.32$ & 0.146 \\
\hline \multicolumn{6}{|l|}{ Liver invasion } \\
\hline Present & $28(48.28)$ & $4.64 \pm 1.24$ & & $274.86 \pm 92.28$ & \\
\hline Absent & $30(51.72)$ & $3.97 \pm 1.35$ & 0.055 & $236.27 \pm 69.13$ & 0.088 \\
\hline \multicolumn{6}{|c|}{ Choledoch invasion } \\
\hline Present & $21(36.20)$ & $4.72 \pm 1.38$ & & $280.86 \pm 98.48$ & \\
\hline Absent & $37(63.80)$ & $4.05 \pm 1.26$ & 0.066 & $240.16 \pm 75.43$ & 0.083 \\
\hline \multicolumn{6}{|l|}{ Diabetes } \\
\hline Present & $9(15.52)$ & $4.39 \pm 1.43$ & & $231.11 \pm 47.61$ & \\
\hline Absent & $49(84.48)$ & $4.27 \pm 1.33$ & 0.799 & $259.27 \pm 90.92$ & 0.371 \\
\hline \multicolumn{6}{|l|}{ Hypertension } \\
\hline Present & $15(25.86)$ & $4.83 \pm 1.44$ & & $265.53 \pm 69.98$ & \\
\hline Absent & $43(74.14)$ & $4.10 \pm 1.26$ & 0.069 & $251.19 \pm 91.30$ & 0.582 \\
\hline \multicolumn{6}{|l|}{ Smoking } \\
\hline Present & $14(24.14)$ & $4.05 \pm 1.27$ & & $247.07 \pm 90.41$ & \\
\hline Absent & $44(75.86)$ & $4.37 \pm 1.36$ & 0.441 & $257.39 \pm 85.39$ & 0.699 \\
\hline
\end{tabular}


Hg. Diabetes mellitus was defined as the use of insulin or the use of oral hypoglycemic drugs or hemoglobin A1c (HbA1c) at a level higher than 6.5\%. Ever-smokers, chewers were assumed for those who smoked, chewed at least once a day for a minimum period of 6 months. Former smokers were assumed for those who had stopped smoking at least 2 years before the interview. For the calculation of pack-years, the amount of tobacco in grams was estimated as 1 per cigarette, 0.5 per bidi and 2 per cigar, cheroot and chutta .

\section{Statistical analysis}

The Shapiro-Wilk test was used to examine normal distribution of the fibrinogen level and platelet count data $(\mathrm{p}=0.85$ and $\mathrm{p}=0.73$, respectively). Because the fibrinogen level data and platelet counts showed normal distribution, all the data were presented by mean $\pm \mathrm{SD}$. The differences between these data and clinic pathological characteristics were evaluated using the Student $t$ test for 2 groups and one-way analysis of variance (ANOVA) for more than 2 groups. Univariate Cox regression analyses were performed for baseline variables to determine indicators with poor prognosis and the multivariate analyses were carried out for the indicators with positive univariate analysis. The Kaplan-Meier survival analysis was used to estimate overall survival and the Mantel's long-rank test was used to compare the differences in it. Pearson's $\chi^{2}$ test was used to determine the significance of the differences for the dichotomous variables. Above statistical analyses were relied on standard SPSS (version 20, IBM, USA) and the Graphpad Prism 5 program. And all p values were based on a two-tailed statistical analysis. All the results were considered statistically significant when $\mathrm{P}<0.05$.

\section{Results}

\section{Patient characteristics}

Among $58 \mathrm{GBC}$ patients of median age 63 years (range from 32 to 86 years), $33(56.90 \%)$ were males and 25 (43.10\%) were females, $42(72.41 \%)$ were adenocarcinoma, 4 (6.90\%) papillary carcinoma, $3(5.17 \%)$ mucinous adenocarcinoma, 3 (5.17\%) tubular adenocarcinoma, 2 (3.45\%) squamous carcinoma, 1 (1.72\%) was malignant adenofibroma, 1 (1.72\%) sarcoma, 1 (1.72\%) neuroendocrine tumors, 1 (1.72\%) adenosquamous carcinoma, 31 (53.45\%) were poorly differentiated carcinomas, $18(31.03 \%)$ moderately differentiated, and 9 (15.52\%) well differentiated. The tumor location: 33 (56.90\%) were in the neck, $13(22.41 \%)$ in the body, $12(20.69 \%)$ in the bottom. The tumor depth (T factor) : 1 (1.72\%) Tis, 6 (10.34\%) T2, 28 (48.28\%)T3, 23 (39.66\%)T4, 34(58.62\%) patients were found with lymph node metastasis, and 18 (31.03\%) were found with distant metastasis. All cases were staged clinically according to the American Joint Committee on Cancer (AJCC, 7th) ${ }^{\text {[24] }}$ : Among 60 cholesterol polyps patients of median age 59 years (range from 31 to 87 years), 27 (45.00\%) were males and $33(55.00 \%)$ were females, 19 (31.67\%) with hypertension, 3 (5.00\%) with diabetes, and $12(20.00 \%)$ smokers; and 60 healthy volunteers of median age 64 years (range from 41 to 84 years), $36(60 \%)$ were males and $24(40.00 \%)$ were females, $10(16.67 \%)$ with hypertension, 3 (5.00\%) with diabetes, and $10(16.67 \%)$ smokers. There was no significant difference in age, sex ratio and comorbidities between the three groups $(p>0.05)$ (Table 1$)$. The serum levels of fibrinogen and platelet counts in patients with GBC: In GBC patients, we found that the serum fibrinogen levels and platelet counts were significantly higher compared with healthy group $(4.29 \pm 1.33$ vs. $3.25 \pm 0.78 \mathrm{~g} / \mathrm{L}$, $\mathrm{p}<0.001$ and $254.90 \pm 85.94$ vs. $219.22 \pm 63.13 \times 10^{9} / \mathrm{L}$, $\mathrm{p}=0.011$, respectively), with cholesterol polyp of gallbladder group $(4.29 \pm 1.33$ vs. $3.16 \pm 0.44 \mathrm{~g} / \mathrm{L}, \mathrm{p}<0.001$ and $254.90 \pm 85.94$ vs. $218.60 \pm 60.05 \times 10^{9} / \mathrm{L}, \mathrm{p}=0.007$, respectively) (Figs. 1 and 2 ).

\section{Correlation between plasma fibrinogen levels, platelet counts, and clinicopathological parameters in patients with GBC}

The serum fibrinogen levels in preoperative $\mathrm{GBC}$ ranged from 1.46 to $6.60 \mathrm{~g} / \mathrm{L}(4.29 \pm 1.33 \mathrm{~g} / \mathrm{L})$. The occurrence of hyperfibrinogenemia was $58.62 \%$ (34/58, cut-off value $4.0 \mathrm{~g} / \mathrm{L})$. Hyperfibrinogenemia was found to be positively correlated with a increased depth of invasion $(\mathrm{p}=0.001)$, LN metastasis $(\mathrm{p}=0.002)$, distant metastasis $(\mathrm{p}<0.001)$

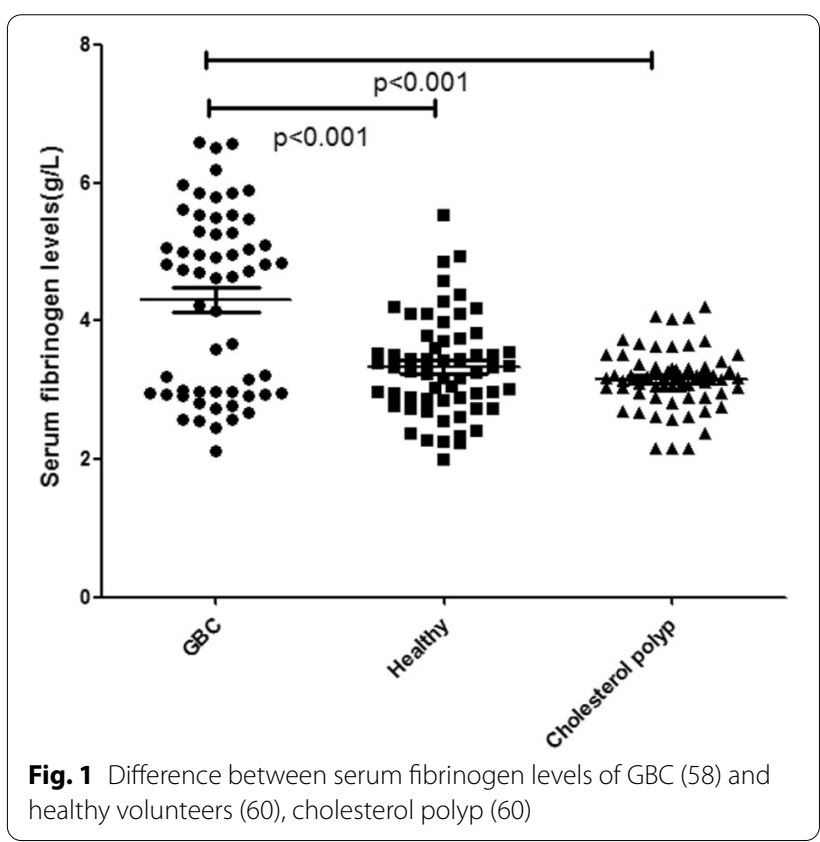




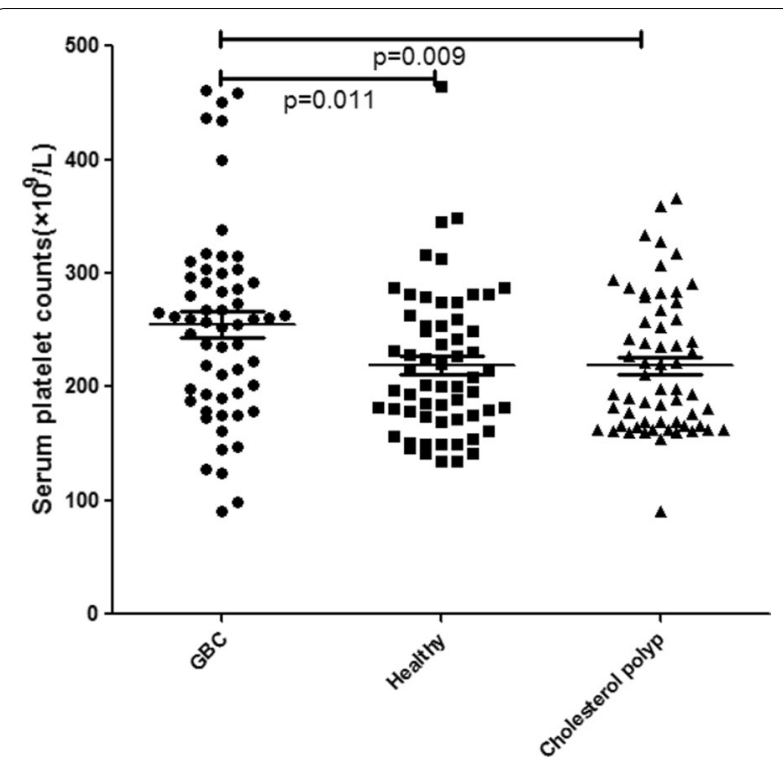

Fig. 2 Difference between serum platelet counts of GBC (58) and healthy volunteers (60), cholesterol polyp (60)

and advanced pathological stages $(\mathrm{p}<0.001)$. No significant correlation was identified between fibrinogen levels and tumor size, tumor location, histological type and histological grading (Table 1). The platelet counts ranged from $91 \times 10^{9} / \mathrm{L}$ to $461 \times 10^{9} / \mathrm{L}\left(254.90 \pm 85.94 \times 10^{9} / \mathrm{L}\right)$. The occurrence of thrombocytosis was $24.14 \%(14 / 58$, cut-off value $\left.300 \times 10^{9} / \mathrm{L}\right)$. Thrombocytosis was positively correlated with distant metastasis $(\mathrm{p}=0.046)$. There was no significant correlation between the platelet count and the larger tumor size, tumor location, increased depth of invasion, LN metastasis and advanced pathological stages (Table 1).

\section{Analysis of the prognostic factors}

To further explore the risk predictors of poor prognosis, the univariate and multivariate analyses of poor prognosis data which were presented in Table 2. The univariate analyses showed that age $(\mathrm{P}=0.031), \mathrm{LN}$ metastasis $(\mathrm{P}<0.001)$, TNM staging $(\mathrm{P}=0.001)$, platelet counts $(P=0.046)$, liver invasion $(P=0.004)$, choledoch invasion $(P=0.002)$, and fibrinogen levels $(P=0.008)$ were predictive factors for poor prognosis. Subsequently, multivariate analyses indicated that $\mathrm{LN}$ metastasis(OR: 4.301; $95 \% \mathrm{Cl} 1.612-11.483 ; \mathrm{P}=0.002)$, TNM staging (OR: 1.003; 95\% $\mathrm{Cl} 0.386-2.806 ; \mathrm{P}<0.001$ ), liver invasion (OR: $2.231 ; 95 \% \mathrm{Cl} 1.172-4.875 ; \mathrm{P}=0.023$ ), choledoch invasion (OR: 2.765; 95\% Cl 1.287-5.769; $\mathrm{P}<0.001$ ), and fibrinogen levels (OR: 1.012; 95\% Cl 0.682-1.876; $\mathrm{P}=0.034$ ) were predictive factors for poor prognosis. Regarding prognosis, the patient in group with low LN metastasis, TNM staging, liver invasion and choledoch invasion was superior than the higher group. The four predictive factors we have detected can actually represent the tumor stage, invasion and metastasis degree,

Table.2 Uni-and multivariate analyses of factors predicting overall survival

\begin{tabular}{|c|c|c|c|c|c|c|}
\hline \multirow[t]{2}{*}{ Variable } & \multicolumn{3}{|c|}{ Univariate analysis } & \multicolumn{3}{|c|}{ Multivariate analysis } \\
\hline & OR & $95 \% \mathrm{Cl}$ & $\mathbf{P}$ & OR & $95 \% \mathrm{Cl}$ & $\mathbf{P}$ \\
\hline Age & 2.189 & $1.109-4.323$ & 0.031 & 1.785 & $0.983-4.843$ & 0.12 \\
\hline Gender & 0.572 & $0.298-1.095$ & 0.092 & & & \\
\hline Tumor depth & 1.37 & $0.701-2.695$ & 0.354 & & & \\
\hline LN metastasis & 4.412 & $2.128-9.148$ & $<0.001$ & 4.301 & $1.612-11.483$ & 0.002 \\
\hline TNM staging & 1.88 & $1.442-2.451$ & 0.001 & 1.003 & $0.386-2.806$ & $<0.001$ \\
\hline Surgery method & 1.09 & $0.552-2.132$ & 0.809 & & & \\
\hline Differentiation degree & 0.647 & $0.408-1.025$ & 0.064 & 1.247 & $0.752-1.793$ & 0.127 \\
\hline Platelet counts & 0.971 & $0.826-1.279$ & 0.046 & & & \\
\hline Pathology & 0.959 & $0.339-2.708$ & 0.937 & & & \\
\hline Jaundice & 1.529 & $0.773-3.026$ & 0.222 & & & \\
\hline Cholelithiasis & 1.501 & $0.790-2.850$ & 0.215 & & & \\
\hline Tumour location & 1.623 & $0.931-2.331$ & 0.321 & & & \\
\hline Liver Invasion & 2.648 & $1.370-5.117$ & 0.004 & 2.321 & $1.172-4.875$ & 0.023 \\
\hline Choledoch Invasion & 3.053 & $1.498-6.224$ & 0.002 & 2.765 & $1.287-5.769$ & 0.001 \\
\hline Diabetes & 0.887 & $0.347-2.269$ & 0.802 & & & \\
\hline Hypertension & 0.92 & $0.448-1.889$ & 0.82 & & & \\
\hline Smoking & 2.02 & $1.493-3.111$ & 0.112 & & & \\
\hline Fibrinogenlevels & 1.493 & $0.792-1.787$ & 0.008 & 1.012 & $0.682-1.876$ & $<0.001$ \\
\hline
\end{tabular}


which have been used as conventional prognostic risk factors in clinical practice. In addition, we found that the serum fibrinogen level $(\geq 4 \mathrm{~g} / \mathrm{L})$ was also prognostic risk factor for poor prognosis. Hence, survival analyse was performed for high-risk and low-risk groups based on this prognostic risk factor.

\section{Correlation between serum fibrinogen levels and platelet counts in the patients with $\mathrm{GBC}$}

To evaluate the correlation between serum fibrinogen levels and platelet counts, we analyzed it with the Spearman Rank Correlation. A significant positive correlation was found between serum fibrinogen levels and platelet counts $(\mathrm{r}=0.397, \mathrm{p}=0.002)$ (Fig. 3).

\section{Correlation between serum fibrinogen levels/ platelet counts and prognosis}

In our study, the median survival time was 8.2 months, and the median follow-up time was 13.6 months (range from 1.5 to 36 months). The follow-up rate reached $87.9 \%$. The 3 -year overall survival rate was $20.7 \%$.The mean survival time of patients with high serum fibrinogen level $(\geq 4 \mathrm{~g} / \mathrm{L})$ was 7.0 months $(n=39,95 \%$ confidence interval (CI): 8.04-15.43), while the low serum fibrinogen level $(<4 \mathrm{~g} / \mathrm{L})$ was 11.4 months $(n=19,95 \%$ confidence interval $(\mathrm{CI})$ : 13.95-26.11) $(\mathrm{p}=0.001)$. The overall survival was worse in high fibrinogen levels group than in low fibrinogen levels group $(\mathrm{p}<0.001)$ (Fig. 4). Furthermore, the levels in TNM stage IV disease were significantly higher than stage III or stage I+II disease $(\mathrm{p}=0.048$ and $\mathrm{p}<0.001$, respectively), and in TNM stage III disease were significantly higher than stage I+II

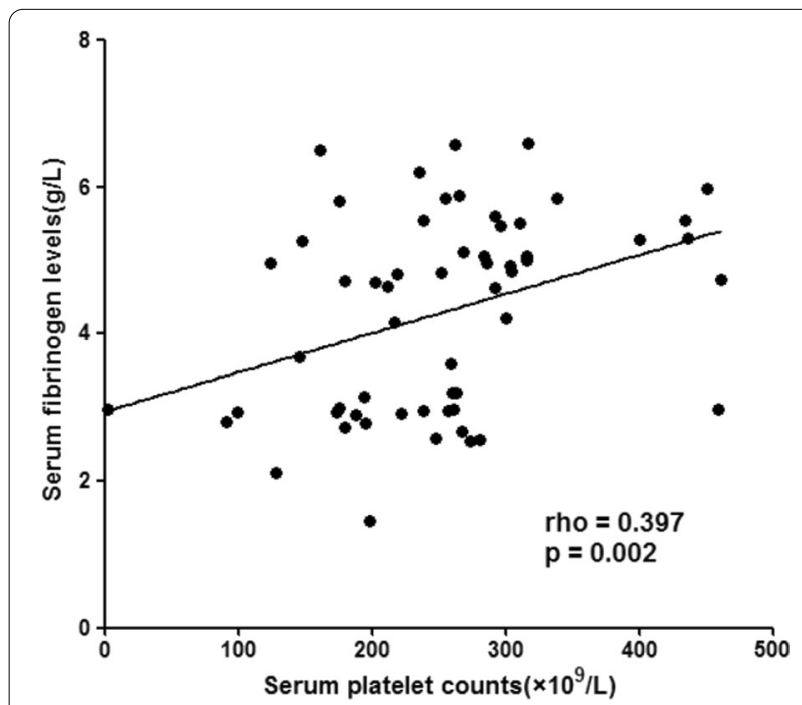

Fig. 3 Correlation between serum fibrinogen levels and platelet counts in GBC

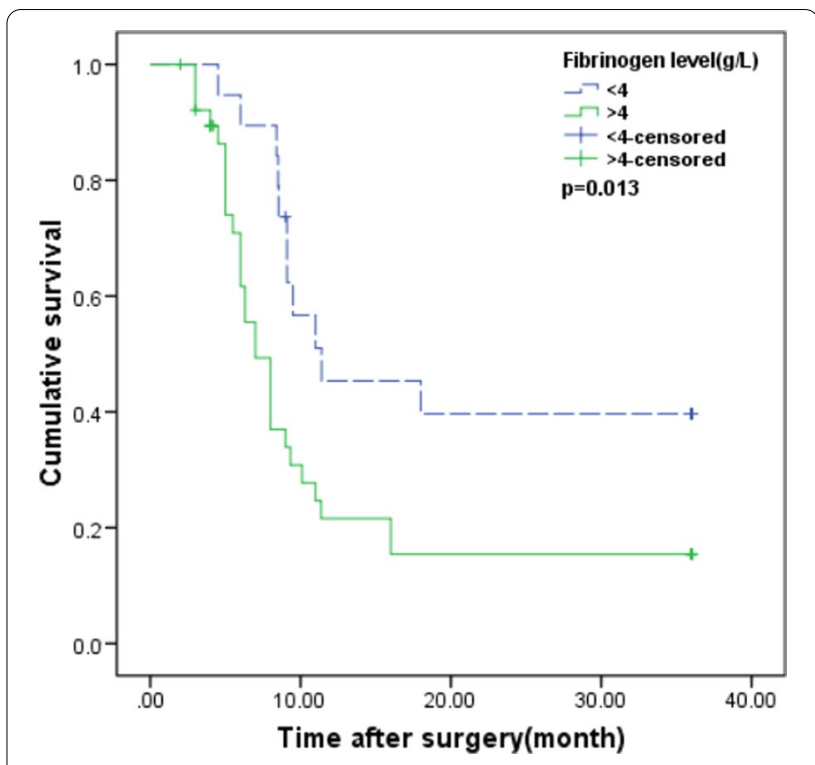

Fig. 4 Survival curve according to serum fibrinogen levels for patients

disease $(p=0.002)$. However, platelet counts were not associated with overall survival ( $p>0.05$ ), but were significantly higher $\left(300 \times 10^{9} / \mathrm{L}\right)$ in $\mathrm{GBC}$ with distant metastasis disease $(\mathrm{p}=0.046)$.

\section{Discussion}

Fibrinogen is a soluble protein synthesized by hepatocytes [9], lung [10] and intestinal epithelium [11], which played a key role in blood clotting, fibrinolysis, inflammatory response, wound healing and neoplasia [12]. Considerable attention has been paid to the association between the progression of malignancies and hyperfibrinogenemia/thrombocytosis. Elevated serum fibrinogen levels and platelet counts were found in various malignancies,such as colorectal cancer [14], hepatic cancer [15], osteosarcoma [6, 7], malignant soft tissue tumors [11], pancreatic cancers [16], gastric cancer [17], and ovarian cancer [18], etc. Our study showed that the incidence of hyperfibrinogenemia and thrombocytosis were $67.2 \%$ (39/58, cut-off value $4.0 \mathrm{~g} / \mathrm{L})$ and $24.1 \%(14 / 58$, cut-off value $300 \times 109 / \mathrm{L})$, respectively, in the GBC patients. And the activation of fibrinolysis and coagulation in GBC patients was frequently related to increased depth of invasion, advanced pathological stages and eventual worse outcomes, so hypercoagulability might be served as a sign of a more aggressive disease. However, we found that hyperfibrinogenemia was associated with poor overall survivals in univariate analysis, but not an independent predictor for prognosis in multivariate analysis. Therefore, the serum fibrinogen might serve as not only a local regulator but also a systematic 
mediator. We also found that thrombocytosis was not associated with depth of invasion, lymph node metastasis, pathological stages, or overall survival, but was significantly higher in GBC with distant metastasis disease. We also observe a significant correlation serum fibrinogen levels and platelet counts $(\mathrm{r}=0.397, \mathrm{p}=0.002)$.

The previous study demonstrated that increased expression of thrombomodulin might reduce the migration of cancer cells by restraining PI3K and Akt [20]. Furthermore,increasing evidence showed that the anticoagulant drugs, such as warfarin and heparin, have antitumor effects both in vivo and in vitro [21]. Anticoagulants, especially the low molecular heparin, have a splendid antitumor effect without fatal bleeding and venous thromboembolism [22]. Other factors including hepatic free fatty acids, non-enzymatic oxysterols or diabetes, can facilitate the progression of other liver diseases including fatty liver, HCC and etc. [23-25].

And for all we knew, no research was carried out to analyzed the clinical significance of serum fibrinogen levels in GBC patients. In the study, we firstly analyzed the clinical significance of pretreatment serum fibrinogen levels in $60 \mathrm{GBC}$ treated by surgery treatment without neoadjuvant treatment or transfusion. Our study showed that hyperfibrinogenemia was significantly related to advanced disease.

The platelet counts have been reported as prognostic factors in various malignancies. Wang et al. proposed that platelet counts were closely correlated with GBC prognosis and could be used to identify the population with a poorer prognosis after surgery [26]. Feng et al. found that preoperative platelet count was a predictive factor for long-term survival in ESCC, especially in nodepositive patients [27]. Ohuchi $\mathrm{M}$ et al. found that a high platelet count is associated with tumor progression and poor survival in patients with esophageal cancer [28]. For thrombocytosis, even inflammation-based scores, such as PLR, was established to analyzes the prognosis of maglinancies [29-32]. The reason for our finding conflicted with previous studies may be that our sample size was relatively too little and the patients with relative advanced stage compared with previous studies.

Although large numbers of studies have shown that the coagulation pathways were associated with tumor progression, the exact mechanism remains inclusive. Fibrinogen was an important component of the extracellular matrix, and hold matrix, tumor cells together through integrins or intercellular adhesion molecule [33]. Fibrinogen generated proliferative signals by binding growth factors, such as fibroblast growth factors (FGF)-2 [34] and vascular endothelial cell growth factors (VEGF) [35], which regulated cellular proliferation and angiogenesis. Fibrinogen deposition around tumor cells enhances the interaction between these cells and platelets, thereby forming microemboli in target organs [36]. Fibrinogen layers help tumor cells block natural killer cytotoxicity with thrombin, which might protect tumor cells from the host's immune system [37].

Platelets, which were produced by mature bone marrow megakaryocytes, and involved in the physiological process of coagulation and in the growth and metastasis of tumors by adhering to, aggregating and releasing their angiogenic contents $[38,39]$. Platelets might release various chemokines, cytokines, proteases, and procoagulants [40]. These agents played key roles in arresting hemorrhage after tissue trauma or vascular injury,blood clotting, tumor cell growth and angiogenesis [41]. Platelets enhance tumor metastasis by expressing immunoregulatory proteins, such as the glucocorticoid induced TNF-related protein to protect tumor cells from the innate immune system [42, 43]. Furthermore, A recent study demonstrated that the interactions between platelets and tumor cells facilitated metastasis by promoting epithelial mesenchymal transition through the TGFB/SMAD and NFKB pathways.They also found that inhibition of these two pathways solely could suppress metastasis in vivo [44].

There are several limitations to our study. First, our cohort was retrospective, and the sample size is relatively small. In order to select patients with a more uniform background, we only included GBC patients treated by potential curative surgery and excluded those received neoadjuvant treatment, which may also limit the general application of the results. Furthermore, larger prospective studies will be needed to confirm these preliminary results.

\section{Conclusions}

Our study demonstrated that hyperfibrinogenemia was a valuable predictor for disease progression and prognosis in GBC. Anticoagulation therapy might be considered to control cancer progression in future studies. Additionally, the serum fibrinogen levels can be a feasible biomarker to assist clinicians in working out better individualization of their therapeutic approach based on the risk stratification.

\footnotetext{
Abbreviations

GBC: Gallbladder carcinoma; TNM: Tumor Node Metastasis; AJCC: American Joint Committee on Cancer; ANOVA: One-way analysis of variance; Cl: Confidence interval; FGF: Fibroblast growth factors; VEGF: Vascular endothelial cell growth factors.
}

\section{Acknowledgements}

Not applicable. 


\section{Authors' contributions}

Data collection $(P C, L J)$, analysis $(P C, L Y Z)$, preparation of manuscript $(P C, L J)$, review and editing of manuscript (PC, YLC). All authors read and approved the final manuscript.

\section{Funding}

This study was supported by grants from the National Natural Science Foundation of China (No. 81672468)

\section{Availability of data and materials}

The data sets analyzed during the current study are available from the corresponding author on reasonable request.

\section{Declarations}

\section{Ethics approval and consent to participate}

Research involving human participants, human material, or human data, have been performed in accordance with the Declaration of Helsinki. The protocol of this study was approved by the Ethics Committee of Affiliated Union Hospital of Fujian Medical University (No. 2021 KY031). and the informed consent was signed by all participants. We confirm that all methods are carried out in accordance with the relevant guidelines and regulations of the ethics committee. This was a retrospective study conducted at the Affiliated Union Hospital of Fujian Medical University, from October 2008 to October 2017. 58 participants were enrolled in the study.

\section{Consent for publication}

Not applicable.

\section{Competing interests}

The authors declare that they have no competing interests.

\section{Author details}

${ }^{1}$ The First Affiliated Hospital, Department of Hepatopancreatobiliary Surgery, Hengyang Medical School, University of South China, Hengyang, Hunan 421001, China. ${ }^{2}$ Department of Hepatobiliary Surgery and Fujian Institute of Hepatobiliary Surgery, Fujian Medical University Union Hospital, Fujian Medical University Cancer Center, Fuzhou, China.

Received: 16 June 2021 Accepted: 27 September 2021 Published online: 07 October 2021

\section{References}

1. Wang X, Lin YK, Lu ZL, Li J. Circular RNA circ-MTO1 serves as a novel potential diagnostic and prognostic biomarker for gallbladder cancer. Eur Rev Med Pharmacol Sci. 2020;24(16):8359-66.

2. Chang Y, Li Q, Wu Q, Chi L, Bi X, Zeng Q, Huo H. Impact of surgical strategies on the survival of gallbladder cancer patients: analysis of 715 cases. World J Surg Oncol. 2020;18(1):142.

3. Marshad M, Maresch M, Al Abbasi T. Intraoperative catheter directed thrombolytic therapy for the treatment of superior mesenteric and portal Vein thrombosis. Int J Surg Case Rep. 2018;53:242-5.

4. Midorikawa R, Hisaka T, Sakai H, Nomura Y, Goto Y, Sato T, Kawahara R, Ishikawa H, Fujita F, Yasunaga M, et al. Clinical and prognostic significance of neoplastic spindle cells in gallbladder cancer. Anticancer Res. 2019;39(8):4561-8.

5. Cao Y, Liang H, Zhang F, Luan Z, Zhao S, Wang XA, Liu S, Bao R, Shu Y, Ma $Q$, et al. Prohibitin overexpression predicts poor prognosis and promotes cell proliferation and invasion through ERK pathway activation in gallbladder cancer. J Exp Clin Cancer Res CR. 2016;35:68.

6. Chava S, Gupta R. Identification of the mutational landscape of gynecological malignancies. J Cancer. 2020;11(16):4870-83.

7. Yang $S$, Ye Z, Wang Z, Wang L. High mobility group box 2 modulates the progression of osteosarcoma and is related with poor prognosis. Ann Transl Med. 2020;8(17):1082.

8. Lisman T, Arefaine B, Adelmeijer J, Zamalloa A, Corcoran E, Smith JG, Bernal W, Patel VC. Global hemostatic status in patients with acute-on-chronic liver failure and septics without underlying liver disease. J Thromb Haemost. 2021;19(1):85-95.

9. Induruwa I, Moroi M, Bonna A, Malcor JD, Howes JM, Warburton EA Farndale RW, Jung SM. Platelet collagen receptor Glycoprotein VI-dimer recognizes fibrinogen and fibrin through their D-domains, contributing to platelet adhesion and activation during thrombus formation. J Thromb Haemost. 2018:16(2):389-404.

10. Kim KH, Park TY, Lee JY, Lee SM, Yim JJ, Yoo CG, Kim YW, Han SK, Yang SC. Prognostic significance of initial platelet counts and fibrinogen level in advanced non-small cell lung cancer. J Korean Med Sci. 2014;29(4):507-11.

11. Asanuma K, Matsumine A, Nakamura T, Matsubara T, Asanuma Y, Oi T, Goto M, Okuno K, Kakimoto T, Yada Y, et al. Impact of plasma fibrinogen levels in benign and malignant soft tissue tumors. Cancer Biomark Sect A Dis Mark. 2016;16(3):453-8.

12. Jo S, Kim I, Lee W, Kim M, Park J, Lee G, Yoon DS. Highly sensitive and wide-range nanoplasmonic detection of fibrinogen using erythrocyte membrane-blanketed nanoparticles. Biosens Bioelectron. 2019;135:216-23

13. Lin D, Bai L, Gan Z, Zhao J, Li G, Aminabhavi TM, Liang H. The role of ferric coagulant on gypsum scaling and ion interception efficiency in nanofiltration at different $\mathrm{pH}$ values: performance and mechanism. Water Res. 2020;175:115695

14. Pedrazzani C, Mantovani G, Salvagno GL, Baldiotti E, Ruzzenente A, lacono C, Lippi G, Guglielmi A. Elevated fibrinogen plasma level is not an independent predictor of poor prognosis in a large cohort of Western patients undergoing surgery for colorectal cancer. World J Gastroenterol. 2016;22(45):9994-10001.

15. Jing W, Peng R, Zhu M, Lv S, Jiang S, Ma J, Ming L. Differential expression and diagnostic significance of pre-albumin, fibrinogen combined with D-dimer in AFP-negative hepatocellular carcinoma. Pathol Oncol Res. 2020;26(3):1669-76.

16. Chung KH, Lee JC, Lee J, Cho IK, Kim J, Jang W, Yoo BC, Hwang JH. Serum fibrinogen as a diagnostic and prognostic biomarker for pancreatic ductal adenocarcinoma. Pancreatology. 2020;20(7):1465-71.

17. Zhang Y, Liu N, Liu C, Cao B, Zhou P, Yang B. High fibrinogen and platelets correlate with poor survival in gastric cancer patients. Ann Clin Lab Sci. 2020;50(4):457-62.

18. Luo Y, Kim HS, Kim M, Lee M, Song YS. Elevated plasma fibrinogen levels and prognosis of epithelial ovarian cancer: a cohort study and metaanalysis. J Gynecol Oncol. 2017;28(3):e36.

19. Smeda M, Przyborowski K, Stojak M, Chlopicki S. The endothelial barrier and cancer metastasis: does the protective facet of platelet function matter? Biochem Pharmacol. 2020;176:113886.

20. Zhu X, Zhao S, Ma X, Cao Z. IL-17F facilitates prostate cancer cell malignant phenotypes via activation of the PI3K/AKT signalling pathway. Andrologia. 2020;52(10):e13750.

21. Khan Y, Zaidi SO, Razak BS, Zaki M, Malik BH. Use of new oral anticoagulants/direct oral anticoagulants in malignant patients. Cureus. 2020;12(2):e7007

22. O'Connell C, Escalante CP, Goldhaber SZ, McBane R, Connors JM, Raskob GE. Treatment of cancer-associated venous thromboembolism with lowmolecular-weight heparin or direct oral anticoagulants: patient selection, controversies, and caveats. The Oncologist. 2021;26(1):e8-16.

23. Bellanti F, Villani R, Tamborra R, Blonda M, lannelli G, di Bello G, Facciorusso A, Poli G, luliano L, Avolio C, et al. Synergistic interaction of fatty acids and oxysterols impairs mitochondrial function and limits liver adaptation during nafld progression. Redox Biol. 2018;15:86-96.

24. Facciorusso A. The influence of diabetes in the pathogenesis and the clinical course of hepatocellular carcinoma: recent findings and new perspectives. Curr Diabetes Rev. 2013;9(5):382-6.

25. Facciorusso A, Licinio R, Carr BI, Di Leo A, Barone M. MEK 1/2 inhibitors in the treatment of hepatocellular carcinoma. Expert Rev Gastroenterol Hepatol. 2015;9(7):993-1003.

26. Wang RT, Zhang LQ, Mu YP, Li JB, Xu XS, Pang Q, Sun LK, Zhang X, Dong SB, Wang $L$, et al. Prognostic significance of preoperative platelet count in patients with gallbladder cancer. World J Gastroenterol. 2015;21(17):5303-10

27. Feng JF, Huang Y, Lu WS, Chen QX. Preoperative platelet count in esophageal squamous cell carcinoma: is it a prognostic factor? Langenbeck's Arch Surg. 2013;398(8):1115-22. 
28. Ohuchi M, Inoue S, Ozaki Y, Ueda K. Platelet count and mean platelet volume are associated with not only bone, soft tissue, and lymph node metastases but also with malignant pleural effusion in lung cancer patients. Neoplasma. 2017;64(1):140-7.

29. Zhou Q, Huang F, He Z, Zuo MZ. Clinicopathological and prognostic significance of platelet count in patients with ovarian cancer. Climacteric J Int Menopause Soc. 2018;21(1):60-8.

30. Deng J, Zhang P, Sun Y, Peng P, Huang Y. Prognostic and clinicopathological significance of platelet to lymphocyte ratio in esophageal cancer: a meta-analysis. J Thorac Dis. 2018;10(3):1522-31.

31. Wang JJ, Wang YL, Ge XX, Xu MD, Chen K, Wu MY, Gong FR, Tao M, Wang WJ, Shou LM, et al. Prognostic values of platelet-associated indicators in resectable lung cancers. Technol Cancer Res Treat. 2019;18:1533033819837261.

32. Shen W, Cui MM, Wang X, Wang RT. Reduced mean platelet volume is associated with poor prognosis in esophageal cancer. Cancer Biomark Sect A Dis Mark. 2018;22(3):559-63.

33. Sheng $L$, Luo M, Sun $X$, Lin N, Mao W, Su D. Serum fibrinogen is an independent prognostic factor in operable nonsmall cell lung cancer. Int J Cancer. 2013;133(11):2720-5.

34. Jin S, Yang C, Huang J, Liu L, Zhang Y, Li S, Zhang L, Sun Q, Yang P. Conditioned medium derived from FGF-2-modified GMSCs enhances migration and angiogenesis of human umbilical vein endothelial cells. Stem Cell Res Ther. 2020;11(1):68.

35. Bai Y, Bai L, Zhou J, Chen H, Zhang L. Sequential delivery of VEGF, FGF-2 and PDGF from the polymeric system enhance HUVECs angiogenesis in vitro and CAM angiogenesis. Cell Immunol. 2018;323:19-32.

36. Laddha AP, Kulkarni YA. VEGF and FGF-2: promising targets for the treatment of respiratory disorders. Respir Med. 2019;156:33-46.
37. Locke M, Francis RJ, Tsaousi E, Longstaff C. Fibrinogen protects neutrophils from the cytotoxic effects of histones and delays neutrophil extracellular trap formation induced by ionomycin. Sci Rep. 2020;10(1):11694.

38. Leblanc $R$, Peyruchaud $O$. The role of platelets and megakaryocytes in bone metastasis. J Bone Oncol. 2016;5(3):109-11.

39. Xu XR, Zhang D, Oswald BE, Carrim N, Wang X, Hou Y, Zhang Q, Lavalle C, McKeown T, Marshall AH, et al. Platelets are versatile cells: new discoveries in hemostasis, thrombosis, immune responses, tumor metastasis and beyond. Crit Rev Clin Lab Sci. 2016;53(6):409-30.

40. Sonmez $\mathrm{O}$, Sonmez M. Role of platelets in immune system and inflammation. Porto Biomed J. 2017;2(6):311-4.

41. Wu YL, Qiao JL, Xu KL, Zeng LY. Research progress on roles of platelets in tissue repair: review. Zhongguo shi yan xue ye xue za zhi. 2016;24(5):1603-6.

42. Li J, Sharkey CC, Wun B, Liesveld JL, King MR. Genetic engineering of platelets to neutralize circulating tumor cells. J Control Release. 2016;228:38-47.

43. Tesfamariam B. Involvement of platelets in tumor cell metastasis. Pharmacol Therap. 2016;157:112-9.

44. Jin M, Gao D, Wang R, Sik A, Liu K. Possible involvement of TGF- $\beta$-SMADmediated epithelial-mesenchymal transition in pro-metastatic property of PAX6. Oncol Rep. 2020;44(2):555-64.

\section{Publisher's Note}

Springer Nature remains neutral with regard to jurisdictional claims in published maps and institutional affiliations.
Ready to submit your research? Choose BMC and benefit from:

- fast, convenient online submission

- thorough peer review by experienced researchers in your field

- rapid publication on acceptance

- support for research data, including large and complex data types

- gold Open Access which fosters wider collaboration and increased citations

- maximum visibility for your research: over $100 \mathrm{M}$ website views per year

At $\mathrm{BMC}$, research is always in progress.

Learn more biomedcentral.com/submissions 